\title{
O cuidado paterno ao filho prematuro no ambiente domiciliar: representações maternas
}

Parental care of premature children at home: maternal representations Cuidado de los padres para niños prematuros en casa: representaciones maternales

\begin{abstract}
Carolina Mathiolli ${ }^{1}$ (C) Rosangela Aparecida Pimenta Ferrari ${ }^{1}$ (B) Cristina Maria Garcia de Lima Parada² (1) Adriana Valongo Zani ${ }^{1}$ (D)
\end{abstract}

1. Universidade Estadual de Londrina. Londrina, PR, Brasil.

2. Universidade Estadual Paulista Júlio Mesquita Filho. Botucatu, SP, Brasil.

Autor correspondente:

Carolina Mathiolli

E-mail: carolina_mathiolli@hotmail.com

Recebido em 03/08/2020.

Aprovado em 21/12/2020

DOl:https://doi.org/10.1590/2177-9465-EAN-2020-0298

\section{Resumo}

Objetivo: Apreender as representações maternas frente à participação dos pais, que foram capacitados ou não por meio de um protocolo de cuidados na unidade neonatal, em relação aos cuidados com o filho prematuro no ambiente domiciliar. Método: Pesquisa qualitativa realizada com mães de prematuros em que os companheiros participaram ou não do protocolo de cuidados ao filho no ambiente hospitalar. A análise foi realizada por meio do Discurso do Sujeito Coletivo. Resultados: Participaram 24 mães, cujos companheiros de 13 realizaram cuidados e 11 não. Surgiram seis ideias centrais e duas ancoragens que foram agrupadas em dois temas: Cuidado paterno no ambiente hospitalar e suas repercussões no cuidado domiciliar; Barreiras para o cuidado paterno. Conclusão e Implicações para a Prática: As mães representam a participação paterna como positiva principalmente aquelas cujos companheiros participaram do protocolo. Porém, observou-se que em algumas situações a não participação paterna estava relacionada com influências culturais e/ou barreiras maternas. Além disso, referiram que o retorno ao trabalho e o medo paterno foram barreiras para o cuidado, independentemente da participação ou não do pai no protocolo. A inserção paterna no cuidado ao filho prematuro no ambiente hospitalar é essencial para a melhoria do cuidado ao bebê e sua família. Palavras-chave: Recém-Nascido Prematuro; Pais; Enfermagem Neonatal; Cuidado da Criança; Unidades de Terapia Intensiva Neonatal.

\begin{abstract}
Objective: to understand the maternal representations in relation to the participation of the parents, who were trained or not through a protocol of care in the neonatal unit, in relation to the care of the premature child in the home environment. Method: qualitative research carried out with mothers of premature infants whose companions participated or not in the protocol of child care in the hospital environment. The analysis was carried out through the Collective Subject Discourse. Results: twenty-four mothers participated whose companions of 13 performed care and 11 did not. Six central ideas and two anchorages emerged that were grouped into two themes: Fatherly care in the hospital environment and its repercussions on home care; Barriers to fatherly care. Conclusion and Implications for Practice: mothers represent paternal participation as positive, especially those whose partners participated in the protocol. However, it was observed that, in some situations, the non-participation was related to cultural influences and/or maternal barriers. In addition, the return to work and paternal fear were barriers to care, regardless of whether or not the father participated in the protocol. The paternal insertion in the care of the premature child in the hospita environment is essential for the improvement of the care for the baby and its family.
\end{abstract}

Keywords: Premature Infant; Parents; Neonatal Nursing; Child Care; Neonatal Intensive Care Units.

\section{Resumen}

Objetivo: comparar las representaciones maternas con respecto a la participación de los padres en el cuidado de niños prematuros en el entorno del hogar, en relación con los padres que participaron o no en un protocolo de cuidado. Metodo: Investigación cualitativa, realizada con madres de bebés prematuros en la que las parejas participaron o no en el protocolo de cuidado del niño en el hospital, de julio a octubre de 2017. El análisis se realizó a través del Discurso del sujeto colectivo. Resultados: 24 madres participaron, de estas 13 las parejas brindaron atención y 11 no. Surgieron seis ideas centrales y dos anclas, que se agruparon en dos temas: la atención paterna en el entorno hospitalario y sus repercusiones en la atención domiciliaria; y Barreras al cuidado paterno. Conclusión e Implicaciones para la Práctica: Las madres que experimentaron la participación de sus parejas en el protocolo de atención representaron este momento con situaciones más satisfactorias en relación con las otras madres. Sin embargo, informaron que regresar al trabajo y el miedo al padre eran barreras para la atención, independientemente de si el padre participó o no en el protocolo. La inserción paterna en el cuidado de niños prematuros en el entorno hospitalario es esencial para mejorar la atención de los bebés prematuros y sus familias.

Palabras clave: Recien Nacido Prematuro; Padres; Enfermería Neonatal; Cuidado del Niño; Unidades de Cuidado Intensivo Neonatal 


\section{INTRODUÇÃO}

O nascimento de um filho prematuro pode ser considerado um momento conflituoso para os pais e sua família, pois vivenciam um extenso e desconhecido período de internação que ocorre nas Unidades de Terapia Intensiva Neonatal (UTIN). ${ }^{1}$ Esta hospitalização pode gerar situações difíceis e, consequentemente, instabilidade familiar, iniciando-se uma fase repleta de obstáculos. Diante da notícia referente à necessidade de permanência no hospital, a família tem seus sonhos e desejos do período gestacional desfeitos. $^{2}$

A inserção do pai nos cuidados com o filho prematuro durante a internação estimula o vínculo entre o bebê e a família e contribui para o cuidado da criança no domicílio após a alta hospitalar. ${ }^{2}$

Percebe-se que tem crescido o desejo do pai, e não somente da mãe, de participar mais ativamente no cuidado ao seu filho. Os homens almejam exercer o seu papel como pai, porém, a experiência da internação, por vezes, não proporciona esta vivência. Apesar de ser um direito dos pais permanecerem o tempo todo com seus filhos no ambiente hospitalar, independentemente da unidade, nota-se que os profissionais atuantes nas unidades neonatais apresentam certa resistência para a inserção deles neste ambiente. A falta de informação, interação e comunicação efetiva com a equipe, somadas à restrição da permanência do homem na unidade, são fatores que limitam a participação deste em exercer a paternidade. Mesmo quando a instituição possui esse acesso aos pais, observa-se que os homens não são incluídos efetivamente nos cuidados dos filhos. Em decorrência desta situação, muitos pais, após seus filhos receberem alta, não se sentem preparados para cuidar, pois não acreditam que são capazes de substituir os profissionais capacitados que conheceram durante a internação do filho. ${ }^{1,3,4}$

É comum após a alta do filho prematuro os pais passarem por uma reorganização de suas vidas, buscando tornarem-se capazes de prestar os cuidados a ele com excelência. No entanto, é sabido que os primeiros dias do filho em casa são difíceis somados ao cansaço físico e emocional vivenciados durante o período de internação. Alguns pais sentem-se culpados por não conseguirem lidar plenamente com a chegada do bebê em casa, embora tenham desejado que o momento ocorresse o mais breve possível. ${ }^{3}$

A preparação dos pais para a alta hospitalar exige que eles sejam capacitados até que se sintam seguros na realização dos cuidados. Dentre eles destacam-se: toque (contato pele a pele, pegar no colo, acalmar, fazer o bebê dormir), higiene (perineal, ocular, oral e banho), aleitamento materno (conhecimento sobre ordenha e auxílio na amamentação), administração via oral (medicações; mamadeira, para os bebês que não estão sendo amamentados; oferta de leite no copo, para os bebês com complementação prescrita) e conhecimento em situações de emergência (manobras de desengasgo e sinais de perigo). ${ }^{5}$ Contudo, é percebido na maioria dos serviços que atendem ao recém-nascido que o preparo para a realização dos cuidados após a alta hospitalar é voltado para as mães.

A participação do homem nos cuidados com o filho é importante para o pai, pois promove a paternidade tornando-o mais participativo, além de proporcionar o fortalecimento do vínculo com o bebê, bem como com sua companheira. Considerando isso, foi elaborado e implementado um protocolo de cuidados direcionado ao pai que promovesse a participação dos homens nos cuidados ao bebê prematuro durante a internação em uma unidade neonatal de um Hospital Universitário na região norte do Paraná.

Diante destes fatos emergiu o seguinte questionamento: Como as mães percebem a participação dos pais, que realizaram ou não o protocolo de cuidados na unidade neonatal, em relação aos cuidados com o filho prematuro no ambiente domiciliar? Portanto, este estudo teve como objetivo apreender as representações maternas frente à participação dos pais, que foram capacitados ou não por meio de um protocolo de cuidados na unidade neonatal, em relação aos cuidados com o filho prematuro no ambiente domiciliar.

\section{MÉTODO}

Consiste em um estudo de abordagem qualitativa integrante de um amplo projeto intitulado "A figura paterna no cuidado ao recém-nascido prematuro e de baixo peso, hospitalizado em Unidade de Terapia Intensiva Neonatal", financiado pelo Conselho Nacional de Desenvolvimento Científico e Tecnológico (CNPq), processo no 448117/2014-2, cujo objetivo geral foi apreender e sistematizar a participação do pai na assistência ao recémnascido prematuro.

O referencial teórico adotado foi a Teoria da Representação Social conceituada como conhecimento socialmente organizado que contribui para a construção de uma realidade comum proveniente dos mitos e crenças da sociedade, ou seja, ao senso comum. ${ }^{6}$ Este referencial vem de encontro com os participantes do estudo, uma vez que busca compreender as representações criadas pelas mães frente o cuidado paterno. As representações são sociais porque o mundo é partilhado entre as diversas pessoas que o compõem, que servem de apoio umas para as outras, muitas vezes de forma convergente, outras de forma conflituosa, para compreendê-lo, administrá-lo ou enfrentá-lo

Esta pesquisa ocorreu após aprovação pelo Comitê de Ética em Pesquisa da Universidade Estadual de Londrina, mediante

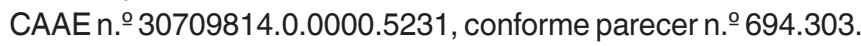

O local do estudo foi o Ambulatório de Especialidades do Hospital Universitário (AEHU) da Universidade Estadual de Londrina. Este ambulatório realiza consultas de seguimento aos prematuros, nascidos no Hospital Universitário da Universidade Estadual de Londrina, com peso inferior a $1500 \mathrm{~g}$ e/ou idade gestacional inferior a 34 semanas. Há acompanhamento pelas enfermeiras residentes do segundo ano do curso de Residência em Enfermagem Neonatal juntamente com a equipe de medicina neonatal até que esses bebês atinjam um ano de idade corrigida.

Participaram deste estudo mães que possuíam filhos com idade gestacional inferior a 34 semanas e/ou peso de nascimento inferior a $1.500 \mathrm{~g}$ e que nasceram entre o período de julho de 2016 e julho de 2017.

Foram critérios de inclusão as mulheres cujos bebês estivessem pelo menos há um mês no domicílio e que residissem com o pai da criança. Este critério foi necessário para que se pudesse 
ter uma visão de como a mãe vivenciava o cuidado que o pai realizava com o filho prematuro no domicílio. Foram excluídas as mulheres cujos companheiros não assumiram a paternidade ou nas situações em que o pai não morava com o filho prematuro.

O protocolo é composto por 14 cuidados: tocar ou acariciar, pegar no colo, fazer canguru, higiene ocular, higiene oral, trocar fraldas, banho, fazer o bebê dormir ou acalmar, conhecimento sobre ordenha, auxiliar no aleitamento materno, administrar medicações via oral, administrar mamadeira (para os bebês que não estão sendo amamentados), ofertar leite no copo (para os bebês com complementação prescrita), conhecimento sobre manobras de desengasgo e sinais de perigo.

Para a execução deste protocolo os pais eram orientados e capacitados para a realização dos cuidados, sendo que os profissionais os avaliavam durante as suas atividades em uma escala (realiza com segurança, executa com certa insegurança, executa com grande insegurança e realiza pela primeira vez). Cabe salientar que este protocolo foi validado por uma equipe de profissionais especialistas em neonatologia com experiência na assistência clínica aos bebês prematuros. Posteriormente, ocorreu a capacitação da equipe por um período de seis meses e, em seguida, houve a implantação do protocolo, que está presente na instituição desde $2013 .{ }^{5}$ Este teve como meta nortear os profissionais para a inserção do pai durante a internação na unidade neonatal e, deste modo, propiciar maior segurança no cuidado de seu filho no domicílio.

Primeiramente, foi realizado o agendamento das entrevistas e para isso o pesquisador identificou, por meio da agenda de consultas da equipe médica, quais os bebês que estavam com agendamento de consulta no ambulatório durante determinada semana. Em seguida, realizou-se ligação telefônica para a mãe do bebê confirmando o dia da consulta de retorno. Neste momento foram convidadas a participarem do estudo, sendo informadas a respeito dos objetivos, garantindo o anonimato e o direito a não participação sem nenhum prejuízo. O contato telefônico com as mães foi realizado no período de julho a outubro de 2017.

Para a definição da amostra, a princípio, foram inclusos todos os recém-nascidos que nasceram no período de julho de 2016 a junho de 2017 e que se mantiveram em atendimento no ambulatório de seguimento no período de julho a outubro de $2017(n=26)$. Destes ocorreram duas recusas devido à indisponibilidade da mãe em comparecer na consulta de retorno do prematuro, totalizando 24 mães. A pesquisa foi interrompida após a realização das entrevistas com todas as mães eleitas para o estudo.

As entrevistas foram realizadas na sala de consulta da enfermagem, de forma individualizada, sem a presença paterna para que não houvesse influência nas respostas das mães e para que elas se sentissem confortáveis. Em muitos casos, os bebês permaneceram junto de seus pais na sala de espera, enquanto as mães eram entrevistadas, pois ambos estavam presentes no dia da consulta e da entrevista.

A coleta de dados ocorreu após a consulta do bebê, com duração de aproximadamente 30 minutos, levando em consideração a interação inicial e a entrevista em si. As entrevistas foram realizadas por quatro residentes de enfermagem que foram capacitadas em relação à pesquisa qualitativa e receberam orientações teórico-práticas relacionadas à abordagem inicial da mãe e a como conduzir a entrevista, além de possíveis entraves que poderiam acontecer durante a coleta de dados, tentando reduzir assim os vieses da pesquisa.

O período de coleta foi de julho a outubro de 2017 por meio de entrevista semiestruturada composta por duas etapas, sendo a primeira a caracterização das mães (idade, escolaridade, estado civil e número de filhos) e a segunda direcionada ao objetivo da pesquisa.

As questões norteadoras utilizadas na entrevista para estimular a fala das mães foram: 1) Conte-me como são distribuídos os cuidados com seu filho, relacionados às atividades domésticas e atividades de trabalho? (Durante a realização dos afazeres domésticos, como vocês se distribuem nos cuidados com o bebê e as atividades domésticas? Nos momentos em que um ou ambos realizam as atividades remuneradas, como organizam os cuidados do bebê?) 2) Quem tem maior vínculo com o bebê e por quê? 3) Durante a internação do seu filho quais cuidados foram realizados pelo pai? Fale sobre isso.

No entanto, em decorrência de existirem mães em que os companheiros/pais participaram ou não do protocolo ocorreu a necessidade de realizar uma questão específica para cada grupo. Para as mães cujos companheiros eram participantes, outra questão utilizada foi: você acredita que o fato do pai ter realizado cuidados (como banho, higiene oral, ocular, etc.) na UTIN/UCIN teve influência nos cuidados no domicílio? Fale-me sobre isso. E para as mães cujos companheiros não participaram do protocolo de cuidados a questão foi: você acredita que o fato do pai não ter tido a oportunidade de realizar cuidados (como banho, higiene oral, ocular, etc.) na UTIN/UCIN teve influência nos cuidados no domicílio? Fale-me sobre isso.

Para a coleta foi utilizada um gravador para que posteriormente as entrevistas fossem transcritas. A transcrição foi realizada pelo pesquisador.

O referencial metodológico adotado para a análise dos dados foi o Discurso do Sujeito Coletivo (DSC) que possibilitou a aproximação com o fenômeno pesquisado.

O Discurso do Sujeito Coletivo (DSC) trata-se de uma forma de procedimento de depoimentos, ou seja, é uma maneira de agrupar em forma de falas únicas as que tenham significados semelhantes no tempo verbal da primeira pessoa do singular. São recriados discursos-sínteses com fragmentos de falas, os quais representam a fala de todos os sujeitos. ${ }^{7}$

Quatro figuras metodológicas foram utilizadas neste estudo: expressões-chaves, ideia central, ancoragem e discurso do sujeito coletivo. As expressões-chaves são fragmentos fiéis dos depoimentos que contêm as representações da fala. A ideia central trata-se da apresentação minuciosa dos significados presentes nos discursos. A ancoragem é definida como uma teoria/ideologia, ou seja, uma crença explicitada no discurso que é proferida pelo indivíduo. $O$ discurso do sujeito coletivo é o agrupamento de expressões-chaves presentes nos depoimentos 
que possuem ideias centrais e/ou ancoragens equivalentes ou complementares, demonstrando o sentido por todos os sujeitos. ${ }^{7}$

Após a transcrição das entrevistas, que compuseram o teste piloto, foi realizada leitura exaustiva de cada discurso pelo pesquisador, posteriormente as transcrições realizou-se feedback informando para as residentes de enfermagem que as entrevistas realizadas estavam adequadas, visto que vinham de encontro ao objetivo do estudo, não sendo necessárias alterações no instrumento de coleta.

Após essa etapa, o pesquisador identificou e destacou as expressões-chaves em cores iguais às que possuíam ideias semelhantes e as distintas em cores diferentes. A etapa de codificação foi validada por dois pesquisadores externos a pesquisa que possuem experiencia no referencial adotado e na temática estudada.

Com isso, as ideias centrais foram encontradas e separadas com base nas expressões-chaves que foram identificadas. Em seguida, reescreveram-se os discursos-sínteses partindo-se dos trechos dos depoimentos das mães sendo utilizada a primeira pessoa do singular de modo que representassem a opinião de todas as participantes. Foram retirados os vícios de linguagem e utilizados conectores a fim de dar sentido ao DSC sem que isso alterasse o significado da frase elaborada pelo participante.

Buscando preservar o anonimato e facilitar o entendimento da análise, para a nomeação das mães cujos companheiros/ pais participaram do protocolo de cuidados foi utilizada a sigla "MS" e para as que o companheiros/pai não participaram foi substituída pela sigla "MN", seguida de sequência numérica respeitando a ordem de realização das entrevistas.

Com o objetivo de apreender as representações maternas nos diferentes níveis de inserção de cuidados do pai na unidade neonatal optou-se por identificar as mães cujo os companheiros foram ou não capacitados por meio de um protocolo de cuidados para o bebê prematuro.

\section{RESULTADOS}

Foram participantes desta pesquisa 24 mães, sendo que destas 13 possuíam companheiros que participaram do protocolo de cuidados voltado para a figura paterna durante a internação do filho prematuro e 11 em que eles não participaram desse protocolo.

Quanto a caracterização das mães segundo a idade: 15 a 19 anos (8,33\%), 20 a 24 anos (33,33\%), 25 a 29 anos (25\%), 30 a 34 anos (12,5\%), 35 a 39 anos (16,66\%) e 40 a 44 anos $(4,16 \%)$. Em relação ao nível de escolaridade verificou-se: ensino fundamental incompleto (12,5\%), ensino fundamental completo (8,33\%), ensino médio incompleto $(20,83 \%)$, ensino médio completo $(45,83 \%)$, ensino superior incompleto $(4,16 \%)$ e ensino superior completo (8,33\%).

No que tange à caracterização dos bebês em relação à idade corrigida variou de: 0 a 3 meses (54,13\%), de 4 a 6 meses $(16,66 \%)$, de 7 a 9 meses (12,5\%) e 10 a 12 meses $(12,5 \%)$ Já sobre a idade cronológica tem-se: de 0 a 3 meses (12,5\%), de 4 a 6 meses $(41,66 \%)$, de 7 a 9 meses $(20,83 \%)$, de 10 a 12 meses $(16,66 \%)$ e 13 meses ou mais $(8,33 \%)$. O período de permanência em casa após a alta hospitalar foi de: 0 a 3 meses (50\%), 4 a 6 meses (16,66\%), 7 a 9 meses (12,5\%) e 10 a 12 meses (20,83\%). Apesar da grande diferença de idade dos recém-nascidos, este foi um fator positivo visto que por se tratar de crianças prematuras o primeiro ano de vida demanda uma maior sobrecarga de cuidados, além disso, este período possibilita compreender as variações da inserção do pai no cuidado.

Quanto à caracterização dos companheiros das mulheres que participaram da pesquisa segundo a idade tem-se: 20 a 24 anos (29,16\%), 25 a 29 anos (20,83\%), 30 a 34 anos (16,66\%), 35 a 39 anos (25\%), 40 a 44 anos (4,16\%) e 45 anos ou mais $(4,16 \%)$. Em relação ao nível de escolaridade verificouse: ensino fundamental incompleto (25\%), ensino fundamental completo (12,5\%), ensino médio incompleto (16,66\%), ensino médio completo $(12,5 \%)$, ensino superior incompleto $(12,5 \%)$ e ensino superior completo (20,83\%).

Em relação a situação conjugal $58,33 \%$ são casados e 45,83\% vivem em união estável. Em relação ao número de filhos, para a maioria das mães este bebê é o primeiro filho $(62,50 \%)$ e $29,16 \%$ e $8,33 \%$ respectivamente possuem dois e três filhos.

Da análise do material empírico surgiram seis ideias centrais (IC) e duas ancoragens (Ac), as quais foram organizadas em dois temas: 1) Cuidado paterno no ambiente hospitalar e suas repercussões no cuidado domiciliar (IC1 - Divisão de cuidados com o companheiro; IC2 - Valorizando a participação do pai no cuidado) e 2) Barreiras para o cuidado paterno (IC3 - Falta de iniciativa paterna e a insegurança materna para o cuidado; IC4 - O medo levando à ausência paterna; IC5 - O trabalho e o medo paterno interferindo no cuidado; IC6 - Influência cultural; Ac1- Ele acha que menina tem que ser cuidada pela mãe; Ac2- Pai não pode cuidar ou trocar "filha-mulher").

\section{Tema 1 - Cuidado paterno no ambiente hospitalar e suas repercussões no cuidado domiciliar}

As mães referem que seus companheiros auxiliam nos cuidados ao filho no domicílio. Pode-se observar nos discursos a seguir que os pais participantes do protocolo desempenham vários cuidados, seja no atendimento ao filho, seja auxiliando nos afazeres domésticos. E em relação aos homens que não realizaram cuidados durante a hospitalização, a ajuda à companheira ocorre mais em momentos pontuais como o período noturno ou aos finais de semanas.

\section{IC1 - Divisão de cuidados com o companheiro}

DSC1: Ele me ajuda nas trocas; quando ela está com cólica ele pega no colo, ajuda no banho, troca, dá "mamá", coloca para dormir, sempre está junto para dar banho. Nos serviços de casa, ele costuma fazer comida, lava a louça e limpa a casa para me ajudar. A gente divide tudo. Um dia um acorda de madrugada, no outro dia o outro acorda (MS1, MS3, MS4, MS9, MS10, MS13).

DSC2: Quem está menos ocupado vai lá e faz, mas geralmente, banho e troca sou eu mesma quem faz. Nos 
serviços domésticos é comigo também. Ele olha o bebê para mim enquanto eu faço a janta (MN8, MN9).

DSC3: Durante o dia sou mais eu que cuido, apesar de haver dias em que a gente reveza um pouco. Quando ele chega do serviço, ele ajuda. Ele dá "mamá" para ela, ele troca, ajuda no banho e coloca nossa filha para dormir. Aí à noite é mais ele quem acorda para fazer mamá e pegar no colo; no final de semana ele me ajuda mais. Ele me ajuda em casa também, limpa e lava a louça (MS2, MS6, MS8, MS11, MS12)

DSC4: Quando o meu marido chega do trabalho, ele me ajuda. Às vezes troca nosso filho, dá "mamá", mas é raro - na verdade ele brinca com ele, enquanto eu limpo a casa. Por causa do trabalho, ele me ajuda mais aos finais de semana e à noite (MN1, MN3, MN4, MN6, MN11).

Outro ponto positivo observado nas representações maternas foi a valorização atribuída ao companheiro frente às atividades que foram realizadas no ambiente hospitalar junto ao filho prematuro. Mesmo em relação aos pais que não puderam participar dos cuidados presentes no protocolo, algumas mães referiram que eles auxiliaram nos cuidados de modo igualitário aos que participaram, conforme identificado nos discursos seguintes.

\section{IC2- Valorizando a participação do pai no cuidado}

DSC5: Durante a internação ele trocou fralda, deu banho - ele que deu o primeiro banho -, fez canguru, trocou fralda, deu leite para ele no "copinho", deu medicação na "colherzinha". À noite, ele quem ia no horário da mamada e eu não ia em nenhum horário da noite. Limpou o "olhinho", a "boquinha". Ainda mais o negócio do 'olhinho' e da "boquinha"; foi ele que fez primeiro. Até hoje ele limpa e faz tudo que aprendeu no hospital, fora que ele ficava todo feliz por estar participando. Cada vez que a gente voltava para o hospital era uma incerteza: “nossa, será que ela vai sobreviver?”. Então ele poder estar participando disso foi bem gratificante. Até limpou a incubadora (MS1-MS12).

DSC6: Durante a internação, ele fazia bastante canguru. Teve uma vez que ele trocou fralda e limpou a "boquinha". Ele tinha bastante medo e a enfermeira insistiu bastante para que ele fizesse (MN4, MN8-MN11).

No entanto, as mães reconhecem que o fato do companheiro ter tido a possibilidade de cuidado no ambiente hospitalar foi um facilitador para o cuidado domiciliar, possibilitando que ele realizasse vários cuidados com o filho.

DSC7: Poder cuidar no hospital teve bastante influência em casa porque a gente perde um pouco o receio de estar manipulando-a, no começo tínhamos medo até de encostarnela. Quando eu engravidei as pessoas falavam para ele que ele ia ter que trocar fralda e ele dizia que não queria trocar fralda. Agora ele troca. Ele ficou com receio por ela ser muito "pequenininha". Ele ficou com medo nos primeiros dias, então ele não trocava, nem dava banho porque ele tinha muito medo. Aí só depois de um tempo que ele começou a fazer os cuidados de banho e troca. A primeira vez que ele pode pegar fez canguru, mas no começo ele tinha muito medo. Ele falava que tinha medo de "quebrar", que era muito pequenininha, mas, aos poucos, sempre fazendo cuidados no hospital, foi perdendo o medo e agora em casa ele não tem nenhum medo. (MS1, MS4, MS10-MS12).

DSC8: Eu o acho muito cuidadoso. Às vezes, ele é até mais cuidadoso do que eu. Acho que pelo fato dele ter acompanhado nosso filho na UTI, hoje em casa ele sabe fazer muito mais coisas; sabe cuidar, mas antes ele não sabia, aprendeu tudo lá. Eu achei mais fácil porque a mãe falar é uma coisa, o enfermeiro falar é outra (MS2, MS5, MS6, MS8, MS9, MS13).

As mães referiram de forma positiva a inserção do pai no cuidado ao filho, pois possibilitou comparar o modo de cuidar que eles vivenciaram em nascimentos de filhos mais velhos $e$ o cuidado possibilitado neste nascimento, enfatizando que a inserção do pai no cuidado proporcionou a ele se tornar mais participativo e vivenciar de forma mais plena sua paternidade.

\begin{abstract}
DSC9: Meu marido já sabia cuidar de criança, pois ele já tem outros filhos de um outro relacionamento e sempre ajudava a cuidar dos filhos, mas ter tido a oportunidade de cuidar no hospital ajudou muito sim - ele costuma dizer que não 'curtiu' os outros filhos tanto como está curtindo esse. Isso porque, quando ele teve os primeiros, não pode cuidar, não foi inserido e nem treinado para realizar os cuidados. Agora, quando tenho que levar nosso filho ao médico, ele quer ir junto à consulta, saber o que o filho tem, como está a saúde dele; é ele que gosta de falar tudo que está acontecendo com nosso filho. Ele é bem participativo (MS3, MS7).
\end{abstract}

Em contrapartida, representações negativas foram referidas pelas mães do estudo frente à falta de iniciativa do companheiro para cuidar do bebê, principalmente nas situações em que ele não participou do cuidado ao filho prematuro no ambiente hospitalar, como observados nos DSC10 e 11.

\section{Tema 2: Barreiras para o cuidado paterno}

\section{IC3 - Falta de iniciativa paterna e insegurança materna para o cuidado}

DSC10: Então, na verdade, como o pai trabalha fora, eu fico com ela. E, geralmente, sou mais eu quem faz todos os cuidados. À noite quando ele chega em casa, às vezes, eu peço "ah, amor, troca a fralda dela" ou "faz o mamá", "faz a mamadeira" (MN6, MN8). 
DSC11: O pai dele não cuida muito dele, pois sou eu que fico mais tempo com nosso filho. Meu marido é muito sossegado, bem "desligadão" para o cuidado; tenho que ficar falando e, às vezes, eu peço: "Tá' precisando trocar ele, vai lá trocar." Porque se depender dele está tudo certo. Na verdade, eu prefiro eu mesma cuidar, pois tenho um pouco de medo de deixar meu marido cuidar (MN2, MN5, MN9, MN10).

Algumas mães percebem de modo negativo que a ausência $e$ não participação do pai no cuidado do filho durante a hospitalização, justificada pelo medo paterno em cuidar, teve como consequência menor interação com o filho hoje no domicílio.

\section{IC4 - O medo levando à ausência paterna}

DSC12: Acho que se meu marido estivesse mais presente quando nosso filho estava internado, ele teria mais carinho por ele. Meu marido não sabe nada sobre nosso filho, ele não sabe de todas as coisas que nosso bebê passou no hospital - quando ele ia, ficava pouco tempo e logo ia embora. Ele não ficava direto no hospital, que eu me lembre. Foi em casa que ele trocou a fralda dele, mas foi uma vez só até agora. Banho ele não dá porque ele diz que o nenê é muito 'molinho' e tem medo, ficando com um pouco de receio. Tanto é que, às vezes, eu preciso deixar nosso filho com ele para sair rapidinho de casa e ele já fala: "não, não vou ficar aqui sozinho com ele." Ele morre de medo, não fica com o bebê sozinho dentro de casa. Só que eu tenho que ficar sozinha com nosso bebê. Se, de repente, o nenê dá uma respirada diferente, ele já me chama. Acho que, se ele tivesse participado dos cuidados lá no hospital, ele teria perdido o medo e conseguiria me ajudar em casa (MN4, MN5).

No entanto, outros fatores independentes do desejo paterno foram dificultadores para a participação do pai, mesmo para os que realizaram cuidados no hospital, pois precisaram fazer readequações na sua rotina. A necessidade de retorno ao trabalho associado ao medo em cuidar do bebê prematuro vieram a dificultar sua presença e participação nos cuidados com o filho prematuro no ambiente hospitalar que foram relatados nos DSC13, 14 e 15.

\section{IC5 - O trabalho e o medo paterno interferindo no} cuidado

DSC13: Ele ia todos os dias depois do trabalho. Que eu me lembre, o que ele mais fez no hospital foi trocar a fralda e fazer canguru, mas ele tinha medo porque ela era muito "pequenininha". O banho foi oferecido, mas ele recusou porque ela era "pequenininha". Ele ficou com medo, nervoso e se desesperou; só depois de quase um mês que ele teve coragem e deu banho. (MS9, MS13).
DSC14: Meu marido não pode cuidar no hospital por conta do trabalho e porque ele tinha medo, mas acho que isto não interferiu, pois aqui em casa ele me ajuda sempre que pode. Se ele está em casa ele dá banho, troca fralda, ele faz tudo. Por exemplo, quando temos consulta aqui [no ambulatório], no banheiro masculino não tem fraldário e eu estava marcando uma consulta e o nenê precisava ser trocado; meu marido entrou no banheiro feminino trancou a porta e trocou ele para mim (MN1, MN3, MN8).

DSC15: No começo, ele ia todo dia, depois não, porque ele estava trabalhando. E era um dia sim e um dia não. Com isso ele acabava passando pouco tempo e logo ele teve que voltar a trabalhar, por isso quem ficou mais tempo com nosso filho no hospital fui eu. Meu marido fez bem pouco cuidado, foi mais essa parte de trocar, que daí quando ela já estava na UCl ele fez pouco porque teve que voltar a trabalhar (MN1-MN6).

Entretanto, há outros fatores que podem interferir na participação do pai. No caso dos pais não participantes do protocolo são os fatores culturais, tais como o estigma de que o homem não deve cuidar da filha por ser do sexo oposto ou de que o papel do pai deve ser de provedor e não de cuidador. Deste modo, há a concepção de que a atribuição de cuidar deve ser delegada à figura materna, o que esteve presente no DSC16.

\section{IC6 - Influência cultural}

Emergiram duas ancoragens, apesar de ambas referirem que filhos do gênero feminino devem ser cuidados pela mãe. Na primeira ancoragem esta é uma visão paterna e a segunda ancoragem está relacionado aos preceitos maternos.

\section{Ac 1 - Ele acha que menina tem que ser cuidada pela} mãe

DSC16: Meu marido é machista, "menina tem que ser cuidada pela mãe". Se fosse menino ele ajudava mais um "pouquinho". E disse também que só vai dar mamá para ela quando ela estiver maiorzinha, porque agora ele tem medo. É como eu digo, na cabeça dele, "menina-mulher"o homem não pode estar tocando nas partes íntimas; porém temos outro filho, um menino, e ele também nunca trocou. Isso porque tem nojo, disse que "vai morrer se tiver coco na fralda". Acho que um pouco é porque meu marido não teve estímulo, era meio retraído, não teve oportunidades, teve uma vida sofrida. Mas, assim, em relação à dedicação, se ele pudesse ele pegava o céu e dava para nossa filha - não só para ela, mas para mim também (MN7, MN9).

\section{Ac 2- Pai não pode cuidar ou trocar "filha-mulher"}

DSC17: Nas tarefas de casa ele me ajuda muito, eu só tenho que agradecer. E também por ser "filha-menina" eu 
não insisto de o pai ter que limpar. Não sei, acho que não é certo, mas minha mãe [avó materna do bebê] sempre diz que pai não pode cuidar ou trocar "filha-mulher", aí fico com isso na cabeça. Gosto de eu mesma cuidar dela. (MN6, MN10).

No entanto, observou-se que muitas vezes são as próprias mulheres que limitam a participação do pai nos cuidados com o filho, tanto dos companheiros que participaram como dos que não participaram dos cuidados, conforme representados nos DSC17 e 18.

DSC18: Eu fico o tempo todo, não deixo ninguém pegar a criança. Minha irmã veio aqui para vê-la esses dias e disse para eu parar de ser chata, deixá-la e a família cuidarem dela, pegar ela um pouquinho, mas eu não deixo não. Acho que é por causa do "mamá" também. Dormir, ela não dorme com o pai de jeito nenhum; no colo do pai não dorme, é só comigo (MS1, MS3-MS5, MS8-MS12).

DSC19: Eu acho que ela (bebê) precisa mais da mãe nesse momento aqui em casa, pois estou mais presente, sou eu que cuido e dou "mamá". Às vezes, ela fica como pai e logo começa a chorar, daí logo pego ela porque ela me quer, a mãe dela, e percebo que quando eu pego no colo ela já para de chorar - é automático. Acho que isso é ocorre pelo tempo que eu fiqueicom ela, os 23 dias da $\mathrm{UCl}$ acompanhando... tive mais presença, acho que ela acabou se acostumando (MN1, MN4-MN6, MN8-MN11).

\section{DISCUSSÃo}

Os resultados revelaram que algumas mães em que seus companheiros participaram do protocolo no ambiente hospitalar perceberam maior envolvimento do pai com o cuidado do filho. Já algumas mães em que os companheiros não estiveram presentes e não participaram destes cuidados, os aspectos culturais, o retorno ao trabalho e o medo foram representados como barreira para o cuidado do filho prematuro no ambiente domiciliar.

Sabe-se que o pai e a mãe possuem representações diferentes em relação ao nascimento, vínculo e cuidado com o bebê, como enfatizado em um estudo realizado com pais e mães de bebês internados em uma UTIN na Noruega. A pesquisa demonstrou que para as mães o nascimento de um filho prematuramente gera a sensação de impotência, enquanto que para o pai trata-se de algo estranho e irreal. Após a alta, a mãe busca fortalecer o vínculo com seu filho que foi prejudicado devido à hospitalização, já o pai busca desenvolver este vínculo. ${ }^{8}$ Isto mostra a importância em estimular a participação do homem nos cuidados com o bebê, visando a criação do vínculo pai-filho precocemente.

As mães representaram a participação do companheiro no cuidado ao filho destacando que este fato possibilitou maior apoio a elas nos momentos de estresse e incertezas e auxiliou o pai em seu empoderamento para o cuidado do filho.
Um estudo realizado com pais de unidade neonatal demonstrou que o homem que possui a possibilidade de ser inserido nos cuidados adquire destreza e segurança com a mesma intensidade que a mãe e deste modo facilita o cuidado do pai junto ao filho prematuro no domicílio. Portanto, a participação paterna é tida como positiva e benéfica, pois propicia confiança e amplia o conhecimento do homem sobre a história do bebê, mesmo para as famílias que já possuem outros filhos. Além disso, auxilia na redução do medo, que foi citado como um importante limitador para a realização de cuidados pelo pai. $^{9}$

No entanto, percebe-se nas representações de algumas mães, cujos companheiros não participaram do protocolo de cuidados, que isto se configurou como barreira para o fortalecimento do vínculo pai e filho e minimização do medo paterno para a maior participação na vida do filho após a alta hospitalar. Tal observação corrobora com um estudo que acompanhou em um período de dez anos pais e mães de recém-nascidos prematuros, o qual identificou que muitos pais não confiam em si próprios para cuidar do bebê em casa, não se sentem "bons pais" e apresentaram elevado nível de estresse e que estes aspectos negativos poderiam ter sido minimizados pelo apoio da equipe de saúde por meio da sua inserção no cuidado ao filho durante o período de hospitalização. ${ }^{4}$

Destaca-se que algumas mães referiram representações negativas frente ao companheiro em relação aos cuidados, enfatizando que apenas realizavam alguma atividade caso fosse solicitado. Porém, é importante ressaltar que algumas mulheres acreditam em conceitos ditados durante muito tempo pela sociedade em relação aos papéis que o pai e a mãe devem exercer na família, sendo o pai provedor e a mãe a cuidadora, independentemente do desejo do pai de participar dos cuidados.

Este fato é reforçado em um estudo realizado com pais e mães a respeito de como se dá o desenvolvimento da paternidade e da maternidade nos primeiros seis meses de vida, apontando que são as mulheres que assumem o cuidado integral dos bebês, o que Ihes causa grande satisfação em realizá-lo. O pai atua como cuidador secundário com função de zelo, sustento, assistência, ajuda e apoio. Dessa forma, ele atua nos momentos em que não há a presença da mulher e quando é necessário. ${ }^{10}$ Diante disso, reforça-se o estigma cultural de que é a mulher quem deve ficar em casa e cuidar dos filhos enquanto o homem sai para trabalhar e ser o provedor. ${ }^{10,11}$

Outro aspecto apontado pelas mães como barreira para que o pai pudesse cuidar do filho está relacionado às demandas do trabalho e o medo de cuidar. As longas jornadas de trabalho dos pais fazem com que eles tenham pouco tempo livre para ficar com o bebê, sendo que muitas vezes o pai opta por aumentar sua carga horária de trabalho devido à preocupação em prover o sustento da casa com a chegada do filho. ${ }^{12}$

Sabe-se que no Brasil a licença paternidade corresponde a apenas cinco dias, os quais começam a ser contados logo após o nascimento do bebê. Sendo assim, este é um obstáculo para que o pai possa vivenciar sua paternidade e auxiliar a mãe, principalmente nos casos de nascimento prematuro e necessidade de longos períodos de internação. ${ }^{13}$ 
Uma pesquisa realizada com pais, cujos filhos prematuros estavam internados na UTIN de uma maternidade do Rio de Janeiro, demostrou que os homens identificaram o prematuro como um ser imaturo, pequeno e frágil, por isso eles sentem medo em realizar cuidados com o filho. Isto leva a um afastamento do pai em relação ao bebê, portanto, é importante fomentar este cuidado, possibilitando assim a promoção do vínculo paibebê. Dessa forma, os homens começam a se acostumar com as características físicas do bebê prematuro e passam a se identificar como pais. ${ }^{14}$ As mães percebem como justificativa para ausência do pai no cuidado o medo frente as fragilidades que um bebê prematuro apresenta.

Outros fatores foram limitadores para a inserção do pai no cuidado como a não crença materna de que o companheiro possa ser capaz de atender às demandas do filho. Muitas vezes, é a mulher quem limita a participação do pai por não confiar no parceiro para cuidar do bebê, sente ciúmes e acredita que por ser a mãe ela é que deve ser a responsável exclusiva pelo cuidado. ${ }^{10,11}$

Em uma pesquisa realizada com mulheres a respeito de sua percepção em relação ao papel paterno percebeu-se que, assim como nesse estudo, a mulher espera que o companheiro seja o provedor da casa e ela a cuidadora. ${ }^{11}$ Diante deste contexto, é necessário o desenvolvimento de estratégias que favoreçam a compreensão da mãe frente ao papel do pai nos cuidados, uma vez que a participação do homem nos cuidados com o bebê possibilita o desenvolvimento emocional, afetivo e social do bebê por meio da criação do filho e a realização de cuidados simples como uma troca de fraldas. Quando a mulher propicia que o homem participe dos cuidados, ela estimula a relação do pai com o bebê e há menos sobrecarga para si, já que possui um companheiro para compartilhar os cuidados. Muitas vezes, o desejo da mãe é que o homem seja companheiro, fonte de apoio e afeto, não sendo necessariamente um parceiro para dividir as tarefas domésticas e cuidados com o bebê. ${ }^{11}$

Sabe-se que quando o pai é participativo tem-se melhores competências sociais, maior empatia, controle emocional, além de atuar no desenvolvimento motor, cognitivo e social do bebê e também colabora para a construção de um apego seguro. Ou seja, a participação do pai nos cuidados com o filho nos primeiros anos de vida é importante tanto para a paternagem quanto para o desenvolvimento do bebê. ${ }^{15}$

Os cuidados básicos como banho, higiene, alimentação, entre outros são relacionadas à mãe, enquanto que aos pais é designado cuidados como lazer, brincadeiras e acalmar a criança, além de ser provedor dos filhos. ${ }^{15}$ Porém, algumas mães não se sentem satisfeitas em serem as responsáveis pelos cuidados com o bebê, expressando sentimentos de insatisfação da participação paterna e desejo de maior envolvimento do pai, embora esses achados sejam mais frequentes em mulheres que são economicamente ativas. ${ }^{12}$

O homem deve ser tratado como membro atuante e participativo nos cuidados com o bebê para o desenvolvimento de sua paternidade, melhoria do bem-estar familiar e das relações entre os membros da família, o que deve começar desde a gestação. As orientações e condutas para uma alta segura do bebê prematuro devem ser voltadas ao pai e a mãe e não apenas para a mulher. ${ }^{11}$

É importante salientar que as representações sociais frente aos gêneros foram um obstáculo para o cuidado paterno visto que algumas mães referiram que o pai não poderia oferecer os cuidados por seu filho pertencer ao sexo feminino, sendo este contexto também enfocado por alguns familiares como avós. Ainda existe em algumas comunidades o senso comum que "pai deve cuidar de filho-homem" e "mãe deve cuidar de filhamulher". E neste estudo foi possível identificar duas ancoragens desta temática.

\section{CONCLUSÃO E IMPLICAÇÕES PARA A PRÁTICA}

Este estudo proporcionou a apreensão das representações maternas frente aos cuidados domiciliares realizados pelos companheiros. Algumas mães representaram a presença dos pais nos cuidados no ambiente hospitalar de forma positiva, referindo satisfação e valorização do papel do pai como cuidador e apoiador. Além disso, perceberam que os companheiros se sentiram mais seguros, capacitados e participativos nos cuidados domiciliares.

Em contrapartida, algumas mães representaram aspectos negativos da não participação do pai nos cuidados no ambiente hospitalar, referindo que se o pai tivesse realizado cuidados durante a internação do bebê ele seria mais participativo, compreensível e não teria tanto medo em cuidar do filho em casa. Cabe salientar que estes aspectos negativos podem estar relacionados a estigmas culturais em que a mulher deve ser responsável pelos cuidados diretos com o bebê e o pai o provedor da casa, dificultando assim a inserção do pai neste processo.

Foi observado que alguns pais não participantes do protocolo de cuidado não realizaram e continuam não realizando cuidados não por sua própria vontade, mas por barreiras maternas em que a mãe não acredita que seu companheiro seja capaz de cuidar do filho ou por influências culturais, visto acreditarem que pelo fato do companheiro ser do sexo masculino ele deve prover o sustento e não o cuidado ao filho.

Outros pontos relevantes que foram identificados como barreira para o cuidado paterno foram as demandas do trabalho e o medo envolvido nos cuidados que tiveram como consequência o menor tempo do pai com o filho no ambiente hospitalar, o que também persistiu no domicílio.

É preciso que o homem seja cada vez mais inserido nos cuidados com o filho e para tal é necessário que os profissionais de saúde valorizem a figura paterna no processo de cuidar e deste modo disseminem essa ideia por toda a família. É preciso dar voz ao novo pai que surge na sociedade, ou seja, um pai mais participativo nos cuidados dos filhos que deseja demonstrar seus afetos, medos e apoio.

Este estudo possibilitou refletir sobre a importância da inserção paterna no cuidado ao filho prematuro no ambiente hospitalar, visto ser essencial para a melhoria do cuidado da criança prematura e sua família. Desta forma foi possível perceber a importância 
da enfermagem neonatal em acolher os pais e as mães durante a internação do bebê, capacitando-os e inserindo-os cada vez mais nos cuidados com seus filhos. Além disso, é preciso que esta equipe seja capacitada, já que a percepção sobre a sua importância propicia menos julgamentos e, consequentemente, maior aproximação dos profissionais com os pais e as mães destes bebês. Dessa maneira surge uma melhor ambiência para a realização de uma assistência de qualidade e humanizada ao prematuro e sua família.

Como implicação para a prática são levantados os seguintes argumentos: o profissional de saúde pode apoiar-se em diretrizes que fortaleçam o cuidado centrado na família, além de identificar como ocorrem as relações familiares e deste modo apoiá-las, respeitando suas crenças e culturas, bem como propiciar que possam vivenciar e/ou desenvolver sua maternagem e paternagem.

As limitações desse estudo estão relacionadas ao fato de que embora todos os pais possuíssem filhos prematuros e o cuidado centrado na família ocorra com frequência por meio de várias estratégias de cuidados desta unidade, em especial com a utilização do protocolo de cuidados paternos, os resultados encontrados foram de apenas um cenário. Neste sentido, recomenda-se a realização de novos estudos em outros cenários para apreender as representações maternas de bebês prematuros diante da participação ou não paterna no cuidado ao filho prematuro ou ainda que se utilize outro referencial teórico e metodológico a fim de contribuir para a prática assistencial de enfermagem neonatal.

\section{FINANCIAMENTO}

O presente trabalho foi realizado com apoio do Conselho Nacional de Desenvolvimento Científico e Tecnológico (CNPq) Processo no 448117/2014-2. Concedido à coordenadora do projeto Prof ${ }^{-}$Dr ${ }^{\text {a }}$ Adriana Valongo Zani, projeto de pesquisa intitulado: A figura paterna no cuidado ao recém-nascido prematuro e de baixo peso, hospitalizado em Unidade de Terapia Intensiva Neonatal.

\section{CONTRIBUIÇÕES DOS AUTORES}

Desenho do estudo. Carolina Mathiolli. Rosangela Aparecida Pimenta Ferrari. Cristina Maria Garcia de Lima Parada. Adriana Valongo Zani.

Coleta ou produção dos dados. Carolina Mathiolli. Adriana Valongo Zani.

Análise de dados. Carolina Mathiolli. Rosangela Aparecida Pimenta Ferrari. Cristina Maria Garcia de Lima Parada. Adriana Valongo Zani.

Interpretação dos resultados. Carolina Mathiolli. Rosangela Aparecida Pimenta Ferrari. Cristina Maria Garcia de Lima Parada. Adriana Valongo Zani.

Redação e revisão crítica do manuscrito. Carolina Mathiolli. Rosangela Aparecida Pimenta Ferrari. Cristina Maria Garcia de Lima Parada. Adriana Valongo Zani.

Aprovação da versão final do artigo. Carolina Mathiolli. Rosangela Aparecida Pimenta Ferrari. Cristina Maria Garcia de Lima Parada. Adriana Valongo Zani.
Responsabilidade por todos os aspectos do conteúdo e a integridade do artigo publicado. Carolina Mathiolli. Rosangela Aparecida Pimenta Ferrari. Cristina Maria Garcia de Lima Parada. Adriana Valongo Zani.

\section{EDITOR ASSOCIADO}

\author{
Eliane Tatsch Neves
}

\section{REFERENCIAS}

1. Petty J, Whiting L, Green J, Fowler C. Parents' views on preparation to care for extremely premature infants at home. Nurs Child Young People. 2018;30(5):22-7. http://dx.doi.org/10.7748/ncyp.2018.e1084. PMid:29975481.

2. Veronez, M. Vivência de mães de bebês prematuros do nascimento a alta: notas de diários de campo. Rev. Gaúcha Enferm. 2017;38(2):e60911. http://dx.doi.org/10.1590/1983-1447.2017.02.60911.

3. Marski BSL, Custodio N, Abreu FCP, Melo DF, Wernet M. Alta hospitalar do recém-nascido prematuro: experiência do pai. Rev Bras Enferm. 2016 abr;69(2):221-8. http://dx.doi.org/10.1590/0034-7167.2016690203i. PMid:27280556.

4. Boykova M. Life after discharge: what parents of preterm infants say about their transition to home. Newborn Infant Nurs Rev. 2016;16(1):5865. http://dx.doi.org/10.1053/j.nainr.2016.03.002.

5. Silva TRS, Silva VCE, Parada CMGL, Zani AV. Validação de um instrumento de cuidados ao prematuro voltado a figura paterna. Rev Eletrônica Acervo Saúde. 2018;10(3):1641-7. http://dx.doi.org/10.25248/ REAS210_2018.

6. Jodelet D. O movimento de retorno ao sujeito e a abordagem das representações sociais. Soc Estado. 2009;24(3):679-712. http://dx.doi. org/10.1590/S0102-69922009000300004.

7. Lefévre F; Lefévre, AMC, Marques, MCC. Discurso do sujeito coletivo, complexidade e auto-organização. Ciênc. saúde coletiva. 2009;4(1):1193204. http://dx.doi.org/10.1590/S1413-81232009000400025.

8. Provenzi L, Barello S, Fumagalli M, Graffigna G, Sirgiovanni I, Savarese $M$ et al. A comparison of maternal and paternal experiences of becoming parents of a very preterm infant. J Obstet Gynecol Neonatal Nurs. 2016;45(4):528-41. http://dx.doi.org/10.1016/j.jogn.2016.04.004 PMid:27266963.

9. Santana JO, Borges KI, Souza DA, Pinto KRTF, Rossetto EG, Zani AV Paternal care for hospitalized premature children: maternal representations. Rev baiana enferm. 2017;31(4):1-8. http://dx.doi.org/10.18471/rbe. v31i4.22310.

10. Martins C, Abreu W, Figueiredo M. Tornar-se pai e mãe: um pape socialmente construído. Revista de Enfermagem Referência. 2014 jun 30;IV Série(2):121-31. http://dx.doi.org/10.12707/RIII1394.

11. Dessen MA, Oliveira MR. Envolvimento paterno durante o nascimento dos filhos: pai "real" e "ideal" na perspectiva materna. Psicol Reflex Crit. 2013;26(1):184-92. http://dx.doi.org/10.1590/S0102-79722013000100020.

12. Castoldi L, Gonçalves TR, Lopes RCS. Envolvimento paterno da gestação ao primeiro ano de vida do bebê. Psicol Estud. 2014;19(2):247-59. http://dx.doi.org/10.1590/1413-737222105008.

13. Constituição de 1988 (BR). Constituição da República Federativa do Brasil Diário Oficial da União [periódico na internet], Brasília (DF), 5 abr 1988 [citado 2018 jun 15].Disponível em:http://www2.camara.leg.br/legin/fed/consti/1988/ constituicao-1988-5-outubro-1988-322142-publicacaooriginal-1-pl.html

14. Soares RLSF, Christoffel MM, Rodrigues EC, Machado MED, Cunha $\mathrm{AL}$. Being a father of a premature newborn at neonatal intensive care unit: from parenthood to fatherhood. Esc Anna Nery. 2015;19(3):409-16. http://dx.doi.org/10.5935/1414-8145.20150054.

15. Gabriel MR, Polli RG, Dall'Agnol LF, Tudge J, Piccinini CA. Envolvimento paterno aos 24 meses de vida da criança. Psicol.: Teor e Pesqui. 2017;33(1):1-10. http://dx.doi.org/10.1590/0102.3772e33410. 